\title{
Analysis of Traces of Tobacco-Specific Nitrosamines (TSNAs) in USP Grade Nicotine, E-Liquids, and Particulate Phase Generated by the Electronic Smoking Devices *
}

\author{
by \\ Serban C. Moldoveanu ${ }^{1}$, Jeff $\mathrm{Zhu}^{2,3}$, and Nancy Qian ${ }^{2}$ \\ ${ }^{1}$ R.J. Reynolds Tobacco Co., Winston-Salem, NC, USA \\ ${ }^{2}$ Eurofins Lancaster Laboratories Inc., Winston-Salem, NC, USA \\ ${ }^{3}$ Current address: ITG Brands, Greensboro, NC, USA
}

\section{SUMMARY}

The present study describes the development of a liquid chromatography tandem mass spectrometry (LC-MS/MS) technique for the analysis of trace levels of four tobaccospecific nitrosamines (TSNAs): nitrosoanabasine (NAB), nitrosoanatabine (NAT), 4-(methylnitrosamino)-1-(3-pyridyl)-1-butanone (NNK), and nitrosonornicotine (NNN). The technique can be applied for the analysis of TSNAs in USP grade nicotine. Nicotine used in e-liquids for the electronic smoking devices is typically obtained from tobacco plant materials (Nicotiana tabacum, Nicotiana rustica) and, although it is purified, it contains besides nicotine low levels of several contaminants such as minor alkaloids. It also contains traces of TSNAs. Analysis of TSNAs in USP grade nicotine is a challenging task since the analyzed samples contain about $10^{+7}-10^{+8}$ times more nicotine than individual TSNAs. Because the analyzed solutions cannot be diluted too much in order to keep the TSNAs level above the limit of quantitation (LOQ), even for apparently good chromatographic separations, the peak tailing of nicotine may generate interferences. The new method of analysis uses a Luna Omega $1.6 \mu \mathrm{m}$ particles chromatographic column for separation and detection on a LCMS/MS instrument with scheduled multiple reaction monitoring (Scheduled MRM). The levels of TSNAs in nicotine of USP purity from four commercial sources varied between 3 to $8 \mathrm{ng} / \mathrm{g} \mathrm{NAB}, 4$ to $20 \mathrm{ng} / \mathrm{g}$ NAT, 30 to $50 \mathrm{ng} / \mathrm{g} \mathrm{NNK}$, and 0.5 to $2 \mathrm{ng} / \mathrm{g}$ for NNN. Besides the analysis of TSNAs in nicotine, the technique has been applied successfully in the analysis of TSNAs in e-liquids and in particulate phase generated by the electronic smoking devices. [Beitr. Tabakforsch. Int. 27 (2017) 86-96]

\section{KEYWORDS}

TSNAs, nicotine, e-liquid, electronic smoking device

\section{ZUSAMMENFASSUNG}

In der vorliegenden Studie wird die Entwicklung einer Methode der Flüssigchromatographie mit Tandem-Massenspektrometrie (LC-MS/MS) zur Analyse von Spurenmengen von vier tabakspezifischen Nitrosaminen (TSNA) beschrieben: Nitrosoanabasin (NAB), Nitrosoanatabin (NAT), 4-(Methylnitrosamino)-1-(3-pyridyl)-1-butanon (NNK) und Nitrosonornikotin (NNN). Die Methode kann für die Analyse von TSNA in Nikotin in USP-Qualität angewendet werden. Das in E-Liquids für elektronische Rauchprodukte verwendete Nikotin wird in der Regel aus Material der Tabakpflanze (Nicotiana tabacum, Nicotiana rustica) gewonnen und es enthält, obwohl es gereinigt wird, außer Nikotin auch geringe Mengen verschiedener Kontaminanten wie zum Beispiel Nebenalkaloide. Des Weiteren enthält es auch Spuren von TSNA. Die Bestimmung von TSNA in USP-Nikotin ist eine Herausforderung, da die 
analysierten Proben ungefähr $10^{+7}-10^{+8} \mathrm{Mal}$ mehr Nikotin als einzelne TSNA enthalten. Da die analysierten Lösungen nicht zu stark verdünnt werden können, damit die TSNAKonzentrationen noch oberhalb der Bestimmungsgrenze (LOQ) liegen, kann das Peak-Tailing von Nikotin, auch bei scheinbar guten chromatographischen Trennungen, Interferenzen hervorrufen. Die neue Analysemethode verwendet eine Luna Omega 1,6- $\mu \mathrm{m}$-Chromatographiesäule für die Trennung und den Nachweis mit einem LC-MS/MS-Gerät mit Scheduled MRM (Scheduled Multiple Reaction Monitoring). Die TSNA-Konzentrationen in USP-Nikotin aus vier Bezugsquellen variierten zwischen 3 und $8 \mathrm{ng} / \mathrm{g}$ $\mathrm{NAB}$, zwischen 4 und $20 \mathrm{ng} / \mathrm{g}$ NAT, zwischen 30 und $50 \mathrm{ng} / \mathrm{g}$ NNK und zwischen 0,5 und $2 \mathrm{ng} / \mathrm{g}$ NNN. Abgesehen von der Analyse von TSNA in Nikotin wurde die Methode auch erfolgreich für die Analyse von TSNA in E-Liquids und in der von elektronischen Rauchgeräten erzeugten Partikelphase angewendet. [Beitr. Tabakforsch. Int. 27 (2017) 86-96]

\section{RESUME}

La présente étude décrit la mise au point d'une technique reposant sur la chromatographie en phase liquide couplée à la spectrométrie de masse en tandem (LC-MS/MS) et destinée à l'analyse des niveaux de trace de quatre nitrosamines spécifiques du tabac (NST) : La nitrosoanabasine (NAB), la nitrosoanatabine (NAT), le 4-(methylnitrosamino)-1-(3-pyridyl)-1-butanone (NKK) et la nitrosonornicotine $(\mathrm{NNN})$. Cette technique peut être appliquée à l'analyse des NST dans la nicotine de qualité USP. La nicotine employée dans les liquides à vapoter des cigarettes électroniques est, d'ordinaire, obtenue à partir de matières issues de la plante de tabac (Nicotiana tabacum, Nicotiana rustica) et malgré une purification, elle contient, en plus de la nicotine, de faibles niveaux de divers contaminants tels que des alcaloïdes mineurs. Elle contient aussi des traces de NST. L'analyse des NST dans la nicotine de qualité USP constitue un défi car les échantillons analysés contiennent environ $10^{+7}-10^{+8}$ fois plus de nicotine que les NST individuels. Sachant que les solutions analysées ne peuvent être diluées à l'excès dans le souci de conserver le niveau de NST au-dessus de la limite de quantification (Ldq), même pour des séparations chromatographiques en apparence correctes, la traînée de la nicotine peut générer des interférences. La nouvelle méthode analytique emploie une colonne chromatographique du Luna Omega (granulométrie $1,6 \mu \mathrm{m}$ ) pour la séparation et la détection sur un instrument LC-MS/MS avec programmation du suivi de réactions multiples (programmation MRM). Les niveaux de NST dans la nicotine de qualité pure USP provenant de quatre sources commerciales varient entre 3 et $8 \mathrm{ng} / \mathrm{g}$ de $\mathrm{NAB}, 4$ et $20 \mathrm{ng} / \mathrm{g}$ de NAT, 30 et $50 \mathrm{ng} / \mathrm{g}$ de NNK et 0,5 et $2 \mathrm{ng} / \mathrm{g}$ de NNN. En plus de l'analyse des NST présents dans la nicotine, cette technique a été appliquée, avec succès, à l'analyse des NST présents dans les liquides à vapoter et dans la phase particulaire générée par les cigarettes électroniques. [Beitr. Tabakforsch. Int. 27 (2017) 86-96]

\section{ABBREVIATIONS}

\begin{tabular}{|c|c|}
\hline I.S. & Internal Standard \\
\hline LC-MS/MS & $\begin{array}{l}\text { Liquid chromatography tandem mass } \\
\text { spectrometry }\end{array}$ \\
\hline LOD & Limit of detection \\
\hline LOQ & Limit of quantitation \\
\hline MRM & Multiple reaction monitoring \\
\hline NAB & Nitrosoanabasine \\
\hline NAT & Nitrosoanatabine \\
\hline NNK & $\begin{array}{l}\text { 4-(Methylnitrosamino)-1-(3-pyridyl)-1- } \\
\text { butanone }\end{array}$ \\
\hline NNN & Nitrosonornicotine \\
\hline $\mathrm{RSD} \%$ & Relative standard deviation \\
\hline TSNA & Tobacco-specific nitrosamine \\
\hline USP & United States Pharmacopeia \\
\hline
\end{tabular}

\section{INTRODUCTION}

Various methods for the analysis of tobacco-specific nitrosamines (TSNAs) have been reported in the literature (1-12). These methods were applied on tobacco, cigarette smoke, and several tobacco products such as moist snuff. With a few exceptions $(6,9)$, the more recent analytical technique of choice for TSNAs analysis is based on LCMS/MS. More recently, specific methods, also based on LC-MS/MS were developed for the analysis of TSNAs in e-liquids (11-14), and effort is continually made to develop even more sensitive methods for the analysis of TSNAs in e-cigarette aerosol condensates (14-16). However, there are no previous reports describing the analysis of TSNAs in nicotine. Nicotine is one of the components of e-liquids used in electronic smoking devices. The nicotine (usually of USP grade) is typically obtained from tobacco plant materials (Nicotiana tabacum, Nicotiana rustica), and although it is purified, it contains besides nicotine some impurities such as myosmine, $\beta$-nicotyrine, and cotinine. It also contains traces of TSNAs. The TSNAs analyzed in this study were nitrosoanabasine (NAB), nitrosoanatabine (NAT), 4-(methylnitrosamino)-1-(3-pyridyl)-1-butanone (NNK), and nitrosonornicotine (NNN). The problem with the analysis of TSNAs in nicotine is related to the fact that the samples contain about $10^{+7}-10^{+8}$ times more nicotine than individual TSNAs. Because the analyzed solutions cannot be diluted too much in order to keep the TSNAs level above the limit of quantitation (LOQ), even for apparently good chromatographic separations the large peak of nicotine may have some tailing which generates interferences. The analysis of TSNAs in nicotine was first attempted in the present study using a LC-MS/MS method successfully applied for the TSNAs analysis in e-liquids (12). The method has the advantage of excellent sensitivity and minimal sample processing (consisting only in the dilution of the sample and addition of internal standards). However, the use of the method from reference (12) showed significant matrix interference for the measurement of TSNAs when the sample was only nicotine. The observed interference consisted of ion suppression for the peaks of the internal standards which were deuterated TSNAs (at about $1 \mathrm{ng} / \mathrm{mL}$ ). In the presence of large nicotine concentrations, the peaks of the internal standards 
became significantly smaller and were even difficult to identify. This implied that the TSNAs detection was also affected. For this reason, a new analytical LC-MS/MS technique was necessary, assuring a better separation of nicotine peak from the TSNAs, offering very low limit of quantitation (LOQ) for the analytes, and not involving extensive sample preparation for the removing of nicotine from the matrix.

\section{EXPERIMENTAL}

\section{Materials and equipment}

Several chemicals including ammonium acetate, ammonium formate, formic acid, and acetonitrile were obtained from Sigma/Aldrich (St. Louis, MO, USA). Nicotine, nitrosoanabasine (NAB), nitrosoanatabine (NAT), 4-(methylnitrosamino)-1-(3-pyridyl)-1-butanone (NNK), nitrosonornicotine (NNN), NAB-d4, NAT-d4, NNK-d4 and NNN-d4 were obtained from Toronto Research Chemicals Inc. (TRC) (North York, ON, Canada). Pure water $(18.2 \mathrm{M} \Omega / \mathrm{cm})$ was obtained from a Barnstead water purification unit (Thermo Fisher Scientific, Waltham, MA, USA). The instruments used for the analysis consisted of an Agilent 1290 HPLC binary system with a binary pump, an autosampler with cooling capability, and a column thermostatted compartment. The HPLC chromatographic separation was achieved on a Luna Omega $1.6 \mu \mathrm{m} \mathrm{C18} 100 \mathrm{~A}$, $100 \times 2.1 \mathrm{~mm}$ from Phenomenex (Torrance, CA, USA). The MS/MS system was an API-6500 triple quadrupole mass spectrometer (AB Sciex, Framingham, MA, USA). The LC-MS/MS system was controlled using Analyst 1.6.2 software, and the peak integration was performed with MultiQuant 3.0.1 software.

\section{Nicotine samples and standards preparation}

The nicotine samples were prepared by dissolving about $0.3 \mathrm{~g}$ nicotine (precisely weighed) in $10 \mathrm{~mL}$ extracting solution. The extracting solution contained $100 \mathrm{mM}$ ammonium acetate in water and four internal standards. The internal standards in the extracting solution were 5-(1-nitroso-2-piperidinyl)pyridine-2,3,4,6-d4 (NAB-d4) at $0.835 \mathrm{ng} / \mathrm{mL}, 1,2,3,6$-tetrahydro-1-nitroso-2,3'-bipyridine$2^{\prime}, 4^{\prime}, 5^{\prime}, 6^{\prime}-\mathrm{d} 4$ (NAT-d4) at $1.00 \mathrm{ng} / \mathrm{mL}, 4$-(methylnitrosamino)-1-(3-pyridyl-d4)-1-butanone (NNK-d4) at $1.00 \mathrm{ng} / \mathrm{mL}$ and 5-(1-nitroso-2-pyrrolidinyl)pyridine-2,3,4,6$\mathrm{d} 4(\mathrm{NNN}-\mathrm{d} 4)$ at $1.00 \mathrm{ng} / \mathrm{mL}$. The calibration was performed using two sets of standards. The first set of calibration standards was obtained by dissolving several levels of NAB, NAT, NNK and NNN in the extracting solution which also contained $3 \%$ pure nicotine $\left(3.0 \times 10^{+7} \mathrm{ng} / \mathrm{mL}\right.$ nicotine $)$ (from TRC) and deuterated internal standards. The concentrations of the TSNAs in $\mathrm{ng} / \mathrm{mL}$ for the first set of calibration standards are given in Table 1.

The second set of calibration standards was used only for verifying the selectivity of the analytical method and was obtained by dissolving several levels of NAB, NAT, NNK and NNN in the extracting solution (containing deuterated internal standards) with no added nicotine. The concentrations of the TSNAs in $\mathrm{ng} / \mathrm{mL}$ in the second set of calibra-
Table 1. Concentrations of TSNAs in $\mathrm{ng} / \mathrm{mL}$ in the first set of calibration standards in the presence of $3 \%$ nicotine.

\begin{tabular}{l|c|c|c|c}
\hline Standard & NAB & NAT & NNK & NNN \\
\hline Std. 1 & 0.0122 & 0.0491 & 0.0504 & 0.0508 \\
Std. 2 & 0.0245 & 0.0982 & 0.1007 & 0.1017 \\
Std. 3 & 0.0980 & 0.3929 & 0.4029 & 0.4068 \\
Std. 4 & 0.2450 & 0.9821 & 1.0072 & 1.0169 \\
Std. 5 & 0.9798 & 3.9285 & 4.0288 & 4.0677 \\
\hline
\end{tabular}

Table 2. Concentrations of TSNAs in $\mathrm{ng} / \mathrm{mL}$ in the second set of calibration standards.

\begin{tabular}{l|rrrr}
\hline Standard & NAB & NAT & NNK & \multicolumn{1}{c}{ NNN } \\
\hline Std. 1 & 0.0122 & 0.0491 & 0.0504 & 0.0508 \\
Std. 2 & 0.0245 & 0.0982 & 0.1007 & 0.1017 \\
Std. 3 & 0.0980 & 0.3929 & 0.4029 & 0.4068 \\
Std. 4 & 0.2450 & 0.9821 & 1.0072 & 1.0169 \\
Std. 5 & 0.9798 & 3.9285 & 4.0288 & 4.0677 \\
Std. 6 & 2.4495 & 9.8213 & 10.0720 & 10.1693 \\
\hline
\end{tabular}

tion standards are given in Table 2.

The samples and the standards were kept at $5{ }^{\circ} \mathrm{C}$ and were further analyzed by a LC-MS/MS technique. The analysis of the same standards within one week interval generated almost identical results indicating good stability of the analyzed solution when kept at $5{ }^{\circ} \mathrm{C}$ for one week. The samples may be stable for a longer period of time, but this was not verified.

\section{Sample preparation for e-liquids and aerosols condensate}

For the preparation of e-liquid samples, the e-liquid was removed from the cartridges by centrifugation, or was simply taken from the bottle with e-liquid replacement for the e-tank. An amount of $1 \mathrm{~g}$ e-liquid was precisely measured and dissolved in $10 \mathrm{~mL}$ extracting solution. For the TSNAs in particulate phase of e-cigarettes or e-tanks, the item was aerosolized (puffed) on a Cerulean SM 450 (Milton Keynes, UK) smoking machine. The collection of particulate phase was performed on Cambridge pads using typical puffing conditions, with $55 \mathrm{~mL}$ puff volume, $3 \mathrm{~s}$ puff, and $30 \mathrm{~s}$ puff interval. From the e-cigarettes 100 puffs were collected, and the Cambridge pads were extracted with $15 \mathrm{~mL}$ extracting solution. From the e-tanks, 200 puffs were collected and the Cambridge pads were extracted with $15 \mathrm{~mL}$ extracting solution. The extracts were subject to LCMS/MS analysis of TSNAs.

\section{HPLC separation conditions}

The amount of sample injected in the HPLC system was $3 \mu \mathrm{L}$. The HPLC separation was performed in gradient conditions. Solution A consisted of an aqueous solution containing 5\% acetonitrile, $10 \mathrm{mM}$ ammonium formate, and brought to $\mathrm{pH} 5.0$ by adding formic acid. Solution B was acetonitrile with $0.2 \%$ added formic acid. The gradient table is given in Table 3 .

The column was kept at $70{ }^{\circ} \mathrm{C}$ during the separation and the backpressure for the HPLC was below 600 bar. 
Table 3. Gradient table for the HPLC separation.

\begin{tabular}{lcc|c}
\hline Time $(\mathrm{min})$ & $\begin{array}{r}\text { Flow rate } \\
(\mu \mathrm{L} / \mathrm{min})\end{array}$ & $\mathrm{A} \%$ & $\mathrm{~B} \%$ \\
\hline Equil 1 min & 600 & 100.0 & 0.0 \\
0.0 & 600 & 100.0 & 0.0 \\
1.7 & 600 & 100.0 & 0.0 \\
3.5 & 600 & 70.0 & 30.0 \\
4.5 & 600 & 40.0 & 60.0 \\
5.0 & 600 & 100.0 & 0.0 \\
\hline
\end{tabular}

\section{MS/MS analysis conditions}

The detection of compounds in the eluate was performed in scheduled multiple reaction monitoring (Scheduled MRM) in positive mode. All the parameters were optimized for generating the highest sensitivity of detection. These parameters included:

- curtain gas CUR $=20 \mathrm{~mL} / \mathrm{min}$

- collision gas $\mathrm{CAD}=4 \mathrm{~mL} / \mathrm{min}$

- ion spray voltage IS $=4500 \mathrm{~V}$

- temperature $\mathrm{TEM}=500{ }^{\circ} \mathrm{C}$

- $\quad$ ion source gas $1 \mathrm{GS} 1=40 \mathrm{~mL} / \mathrm{min}$

- $\quad$ ion source gas $2 \mathrm{GS} 2=50 \mathrm{~mL} / \mathrm{min}$

- entrance potential $\mathrm{EP}=10 \mathrm{~V}$

- $\quad$ target scan time $=0.11 \mathrm{~s}$

- $\quad$ scheduled MRM detection window $=40 \mathrm{~s}$.

Other parameters including the analyzed ions are given in Table 4.

\section{Examples of extracted chromatograms}

The extracted ion chromatogram for the internal standards

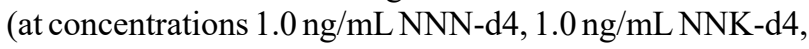
$1.0 \mathrm{ng} / \mathrm{mL}$ NAT-d4, and $0.835 \mathrm{ng} / \mathrm{mL}$ NAB-d4) in the presence of $3.0 \times 10^{+7} \mathrm{ng} / \mathrm{mL}$ nicotine is given in Figure 1 . The extracted ion chromatogram for calibration standard Std. 2 (at the concentrations NAT $0.0982 \mathrm{ng} / \mathrm{mL}, \mathrm{NAB}$ $0.0245 \mathrm{ng} / \mathrm{mL}$, NNK $0.1007 \mathrm{ng} / \mathrm{mL}$ and NNN 0.1017 $\mathrm{ng} / \mathrm{mL}$ ) in a solution containing $3 \%$ nicotine and the internal standards is shown in Figure 2. As shown in Figure 2, even at concentrations of $24.5 \mathrm{pg} / \mathrm{mL}$ NAB and around $100 \mathrm{pg} / \mathrm{mL}$ for the other TSNAs the chromatogram shows good resolution and good peak shape, in a solution containing $3 \%$ nicotine and the internal standards.
Table 5. The values for parameters $a, b$, and the $R^{2}$ for the quantitation of TSNAs in the presence of $3 \%$ nicotine.

\begin{tabular}{l|c|c|c|c}
\hline Compound & I.S. & $a$ & $b$ & $R^{2}$ \\
\hline NAB & NAB-d4 & $9.1258 \mathrm{e}-1$ & $-1.1868 \mathrm{e}-2$ & 0.9998 \\
NAT & NAT-d4 & $1.0421 \mathrm{e} 0$ & $-3.5315 \mathrm{e}-2$ & 0.9998 \\
NNK & NNK-d4 & $9.9914 \mathrm{e}-1$ & $-8.0306 \mathrm{e}-2$ & 0.9987 \\
NNN & NNN-d4 & $1.0073 \mathrm{e} 0$ & $-1.4665 \mathrm{e}-1$ & 0.9994 \\
\hline
\end{tabular}

\section{Quantitation of TSNAs in the presence of 3\% nicotine}

The quantitation of TSNAs has been performed using calibration lines based on the first set of standards made with 3\% pure nicotine (from TRC) and containing deuterated TSNAs as internal standards. All the calibrations were linear and equations of the form $Y=a X+b$ were obtained for each analyte, where $Y$ is the amount of TSNA in $\mathrm{ng} / \mathrm{mL}$ and $X$ is the ratio (peak area analyte)/(peak area internal standard). The internal standard used for each analyte was the corresponding deuterated compound. The values for parameters $a, b$, and the $R^{2}$ (square of the Pearson productmoment correlation coefficient) are given in Table 5 . The samples were run in duplicate.

As shown in Table 5, three $R^{2}$ values for the linear calibrations were higher than 0.999 , and one (for NNK) was higher than 0.998 .

\section{Validation of the analytical procedure}

For the validation of this analytical procedure, the typical parameters recommended for this process were considered (15). These parameters included:
1) specificity
2) selectivity
3) precision
4) repeatability/reproducibility
5) accuracy
6) linearity and linear range
7) limit of detection (LOD) and limit of quantitation (LOQ)
8) recovery
9) robustness/ruggedness/stability.

1) Specificity (the quality of the method to produce a response for a single analyte in the presence of other components in the matrix) was one of the main objectives

Table 4. Other parameters for the MS/MS detection.

\begin{tabular}{l|c|c|c|c|c|c}
\hline Compound & $\begin{array}{c}\text { Ion for } \\
\text { quadrupole 1 }\end{array}$ & $\begin{array}{c}\text { lon for } \\
\text { quadrupole 3 }\end{array}$ & $\begin{array}{c}\text { Elution time } \\
(\mathrm{min})\end{array}$ & $\begin{array}{c}\text { Declustering } \\
\text { potential }(\mathrm{V})\end{array}$ & $\begin{array}{c}\text { Collision energy } \\
(\mathrm{V})\end{array}$ & $\begin{array}{c}\text { Collision cell exit } \\
\text { potential (V) }\end{array}$ \\
\hline NNN & 178.1 & 148.1 & 3.18 & 30 & 15 & 9 \\
NNN-d4 & 182.1 & 152.1 & 3.16 & 30 & 16 & 9 \\
NAT & 190.1 & 160.1 & 3.71 & 28 & 15.5 & 10 \\
NAT-d4 & 194.1 & 164.1 & 3.70 & 28 & 16 & 10 \\
NAB & 192.1 & 162.1 & 3.82 & 26 & 18 & 11 \\
NAB-d4 & 196.1 & 166.1 & 3.80 & 26 & 17 & 10 \\
NNK & 208.1 & 122.1 & 3.48 & 30 & 17.6 & 13 \\
NNK-d4 & 212.1 & 126.1 & 3.46 & 30 & 16 & 12 \\
\hline
\end{tabular}




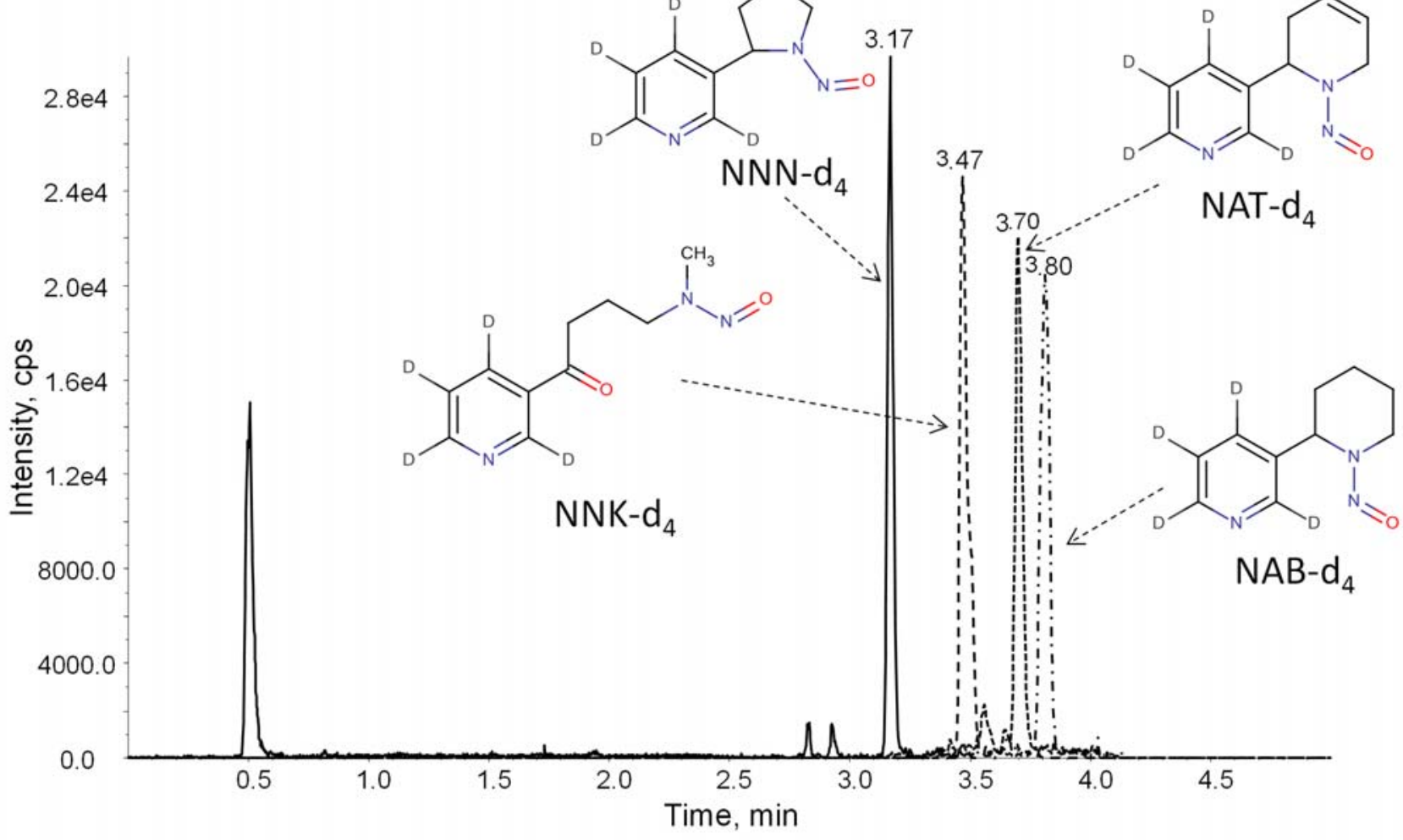

Figure 1. Extracted ion chromatogram obtained by the present method for the internal standards (at the concentrations $1.0 \mathrm{ng} / \mathrm{mL}$ NNN-d4, $1.0 \mathrm{ng} / \mathrm{mL}$ NNK-d4, $1.0 \mathrm{ng} / \mathrm{mL}$ NAT-d4, and $0.835 \mathrm{ng} / \mathrm{mL}$ NAB-d4) in the presence of $3.0 \times 10^{+7} \mathrm{ng} / \mathrm{mL}$ nicotine. The monitored transitions were 196.1 to 166.1 for NAB-d4, 194.1 to 164.1 for NAT-d4, 212.1 to 126.1 for NNK-d4, and 182.1 to 152.1 for NNN-d4.

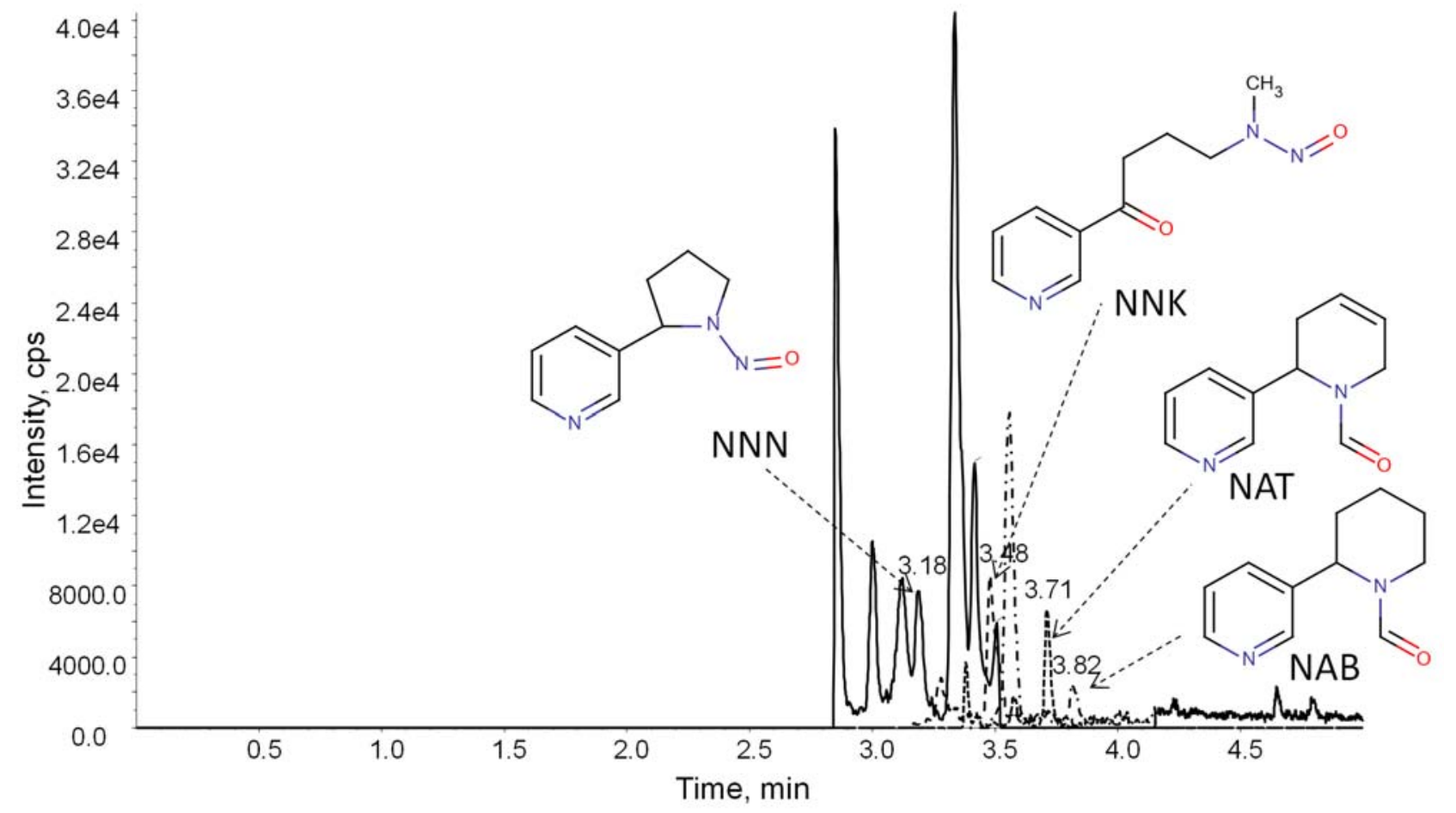

Figure 2. Extracted ion chromatogram obtained by the present method for calibration standard Std. 2 (at the concentrations NAT $0.0982 \mathrm{ng} / \mathrm{mL}$, NAB $0.0245 \mathrm{ng} / \mathrm{mL}$, NNK $0.1007 \mathrm{ng} / \mathrm{mL}$ and NNN $0.1017 \mathrm{ng} / \mathrm{mL}$ ) in a solution containing $3 \%$ nicotine and the internal standards. The monitored transitions were 192.1 to 162.1 for NAB, 190.1 to 160.1 for NAT, 208.1 to 122.1 for NNK, and 178.1 to 148.1 for NNN. 
to be achieved in this study. Although nicotine elutes at $2.0 \mathrm{~min}$ and the elution time for NNN (the first to elute from TSNAs) is at $3.18 \mathrm{~min}$, the injection of a sample containing $3 \%$ nicotine generates an overloaded very broad peak. To confirm that the TSNAs quantitation is not affected by the presence of nicotine, calibrations with the second set of standards were performed. The calibration lines based on a second set of standards made in absence of nicotine were also linear and equations of the form $Y=a X+b$ were obtained for each analyte similarly to those obtained in the presence of $3 \%$ nicotine. The values for parameters $a, b$, and the $R^{2}$ (square of the Pearson product-moment correlation coefficient) are given in Table 6. The samples were run in duplicate.

The comparison of Table 5 and Table 6 indicate that the values for parameters $a$ and $b$ are very similar, and $R^{2}$ values are very close to 1.0 in both cases. This result showed that the effect of ion suppression caused by nicotine is not seen by using the new method for TSNA analysis.

2) Selectivity of the method is assured by the use of individual MRM transitions and retention times for each analyte and internal standard.

3) Precision was measured for the lowest standard solution (Std.1 in Table 1), by repeatedly injecting the sample (in three consecutive days). From three separate injections, the following RSD\% were obtained: NAB 7.3\%, NAT 5.9\%, NNK 9.9\%, NNN 3.7\%. These results indicated excellent precision of the procedure.

4) Only repeatability of the procedure has been evaluated (reproducibility, refers to results from the same method, obtained in different laboratories). The results from three consecutive days were indicated as precision and all the results indicated RSD $\%$ below $10 \%$ for the lowest standard. 5) The accuracy of the method was evaluated by comparing the calculated results for the TSNAs standards (in the presence of $3 \%$ nicotine) obtained from the calibration curves and the values taken for analysis. These results are indicated in Table 7.

The results from Table 7 indicate that the method has an excellent accuracy.

6) The linear range for each calibration results from Table 1 and the linearity from Table 6 . The range of calibration was not very large, between about $10 \mathrm{pg} / \mathrm{mL}$ to $1 \mathrm{ng} / \mathrm{mL}$ for $\mathrm{NAB}$ and between about $50 \mathrm{pg} / \mathrm{mL}$ and $4 \mathrm{ng} / \mathrm{mL}$ for NAT, NNK and NNN. This range was covering the expected levels of TSNAs in the samples. In this range, the values for $R^{2}$ were all very close to 1.0 showing very good linearity.

7) The LOD and LOQ for this method was obtained using the standard deviation SD value for three separate injections of the lowest standard, with LOD $=3 \mathrm{SD}$ and LOQ $=$
Table 6. The values for parameters $a, b$, and the $R^{2}$ for the quantitation of TSNAs in the absence of nicotine.

\begin{tabular}{l|c|c|c|c}
\hline Compound & I.S. & $a$ & $b$ & $R^{2}$ \\
\hline NAB & NAB-d4 & $1.0043 \mathrm{e} 0$ & $-9.7481 \mathrm{e}-4$ & 0.9994 \\
NAT & NAT-d4 & $1.1777 \mathrm{e} 0$ & $-1.8931 \mathrm{e}-2$ & 9.9990 \\
NNK & NNK-d4 & $1.0076 \mathrm{e} 0$ & $-2.2986 \mathrm{e}-2$ & 0.9995 \\
NNN & NNN-d4 & $1.0725 \mathrm{e} 0$ & $-1.2361 \mathrm{e}-2$ & 0.9995 \\
\hline
\end{tabular}

Table 7. Levels of TSNAs taken in the analysis and calculated results based on calibration curves. All numbers represent $\mathrm{ng} / \mathrm{mL}$ of each analyte.

\begin{tabular}{lr|r|r|r}
\hline Standard taken & \multicolumn{1}{c|}{ NAB } & \multicolumn{1}{c}{ NAT } & NNK & \multicolumn{1}{c}{ NNN } \\
\hline Std. 1 & 0.0122 & 0.0491 & 0.0504 & 0.0508 \\
Difference calculated & -0.0038 & -0.0064 & 0.0014 & -0.0071 \\
Std. 2 & 0.0245 & 0.0982 & 0.1007 & 0.1017 \\
Difference calculated & 0.0005 & -0.0033 & -0.0031 & 0.0073 \\
Std. 3 & 0.0980 & 0.3929 & 0.4029 & 0.4068 \\
Difference calculated & 0.0020 & 0.0268 & 0.0160 & 0.0033 \\
Std. 4 & 0.2450 & 0.9821 & 1.0072 & 1.0169 \\
Difference calculated & 0.0034 & -0.0237 & 0.0210 & 0.0259 \\
Std. 5 & 0.9798 & 3.9285 & 4.0288 & 4.0677 \\
Difference calculated & -0.0012 & 0.0030 & -0.0075 & -0.0092 \\
\hline & & & &
\end{tabular}

Table 8. Values for LOD and LOQ obtained in $\mathrm{pg} / \mathrm{mL}$ from the SD values of the lowest calibration standard.

\begin{tabular}{l|c|r|c|c}
\hline & NAB & NAT & NNK & NNN \\
\hline LOD & 1.9 & 7.5 & 15.4 & 4.8 \\
LOQ & 6.2 & 25.2 & 51.3 & 16.1 \\
\hline
\end{tabular}

$10 \mathrm{SD}$. The values for LOD and LOQ for each analyte are indicated in Table 8.

8) Recovery was evaluated by adding to four samples of nicotine (see Table 10) at about $3 \%$ concentration in the extracting solution two levels of TSNAs. One level was 1/5 from TSNAs present in Std. 3 and the other was 1/5 from TSNAs present in Std. 5. Together with the added TSNAs were added the corresponding internal standards and the nicotine present in the standard. The recoveries were very good, and the results are exemplified only for sample Spl. Nicotine 1 (four nicotine samples were studied indicated as Spl. Nicotine1, Spl. Nicotine 2...) in Table 9.

As shown in Table 9, the recovery \% was very good for Spl. Nicotine 1 (replicate 1) and similar levels of recovery were obtained for all the evaluated samples.

Table 9. Example of recovery \% for Spl. Nicotine 1 (replicate 1) with two levels of added TSNAs (measured levels in $\mathrm{ng} / \mathrm{mL}$ ).

\begin{tabular}{l|c|c|c|r|r|r|r}
\hline Analyte & Measured & $+1 / 5$ Std 3 & Measured & \% Recovery & $+1 / 5$ Std 5 & Measured & \% Recovery \\
\hline NAB & 0.2229 & 0.0196 & 0.2352 & 97.00 & 0.1960 & 0.3938 \\
NAT & 0.1518 & 0.0786 & 0.2143 & 93.00 & 0.7857 & 0.9469 & 101.00 \\
NNK & 1.7712 & 0.0806 & 1.8333 & 99.00 & 0.8056 & 2.5253 \\
NNN & 0.0531 & 0.0814 & 0.1385 & 103.00 & 0.8135 & 0.8406 \\
\hline
\end{tabular}


9) Robustness/ruggedness/stability refers to the quality of an analysis to not be influenced by small experimental modifications, reproducibility under a variety of conditions such as different laboratories, or instruments, and stability of the results obtained in longer periods of time. These aspects of the method were only partially verified, and it was only possible to evaluate the robustness of the method. The analysis was not practiced in different laboratories, different instruments, and it was not verified for a long period of time. However, the repetition of analyses on different days and with different sets of mobile phases generated results with very small variations. It can be concluded that the method is robust, while ruggedness and stability were not yet proven.

\section{RESULTS AND DISCUSSION}

Results for TSNA analysis in nicotine using a literature method

The initial attempt to analyze TSNAs in nicotine utilized a method with the separation on a Kinetex EVO C18 column $2.1 \times 100 \mathrm{~mm}$ with $1.7 \mu \mathrm{m}$ particles, with gradient elution. The gradient used solution A: $10 \mathrm{mM}$ ammonium acetate at pH 6.75 in $95 \%$ water, $5 \%$ acetonitrile and solution B: $0.1 \%$ acetic acid in acetonitrile. The detection was performed on the same instrument as described in this study (see Experimental part), using MRM detection in positive mode. The same specific transitions from precursor ion to product ion, specific for each TSNA compound as described in Table 4 were applied for detection. Samples were injected at $3 \mu \mathrm{L}$ volume. The analysis used as internal standards NAB-d4 at $0.835 \mathrm{ng} / \mathrm{mL}, \mathrm{NAT}-\mathrm{d} 4$ at $1.00 \mathrm{ng} / \mathrm{mL}$, $\mathrm{NNK}-\mathrm{d} 4$ at $1.00 \mathrm{ng} / \mathrm{mL}$ and NNN-d4 at $1.00 \mathrm{ng} / \mathrm{mL}$. The chromatogram obtained for the I.S. in solution and in the absence of nicotine is shown in Figure 3.

The method from the literature (12) was adequate for the analysis of TSNAs in e-liquids and e-cigarettes. However, for the purpose of analyzing TSNAs in USP grade nicotine samples, a 3\% nicotine solution containing deuterated internal standards at the same level as those shown in Figure 3 was prepared. This solution was analyzed by the method from the literature (12). The results of this analysis are shown in Figure 4. The results from Figure 4 showed a severe suppression of the ions for deuterated TSNAs in a solution containing about $1 \mathrm{ng} / \mathrm{mL}$ of each TSNA-d4 in the presence of $3 \%$ nicotine. Although nicotine elutes earlier than TSNAs, because of its large quantity and high sensitivity of the detection, the nicotine peak is overloaded and extends significantly after the expected retention time. Even the internal standards cannot be properly detected in the presence of nicotine at 3\% level, and the analytes in the nicotine samples were expected to be at even lower level than the I.S. In contrast, the method described in this present study allows the analysis of TSNAs in the presence of nicotine.

Results for analysis of TSNAs in nicotine using present method

Four USP grade nicotine samples from different vendors/batches were evaluated for TSNA content for this purpose, about $0.3 \mathrm{~g}$ nicotine (precisely weighed) were

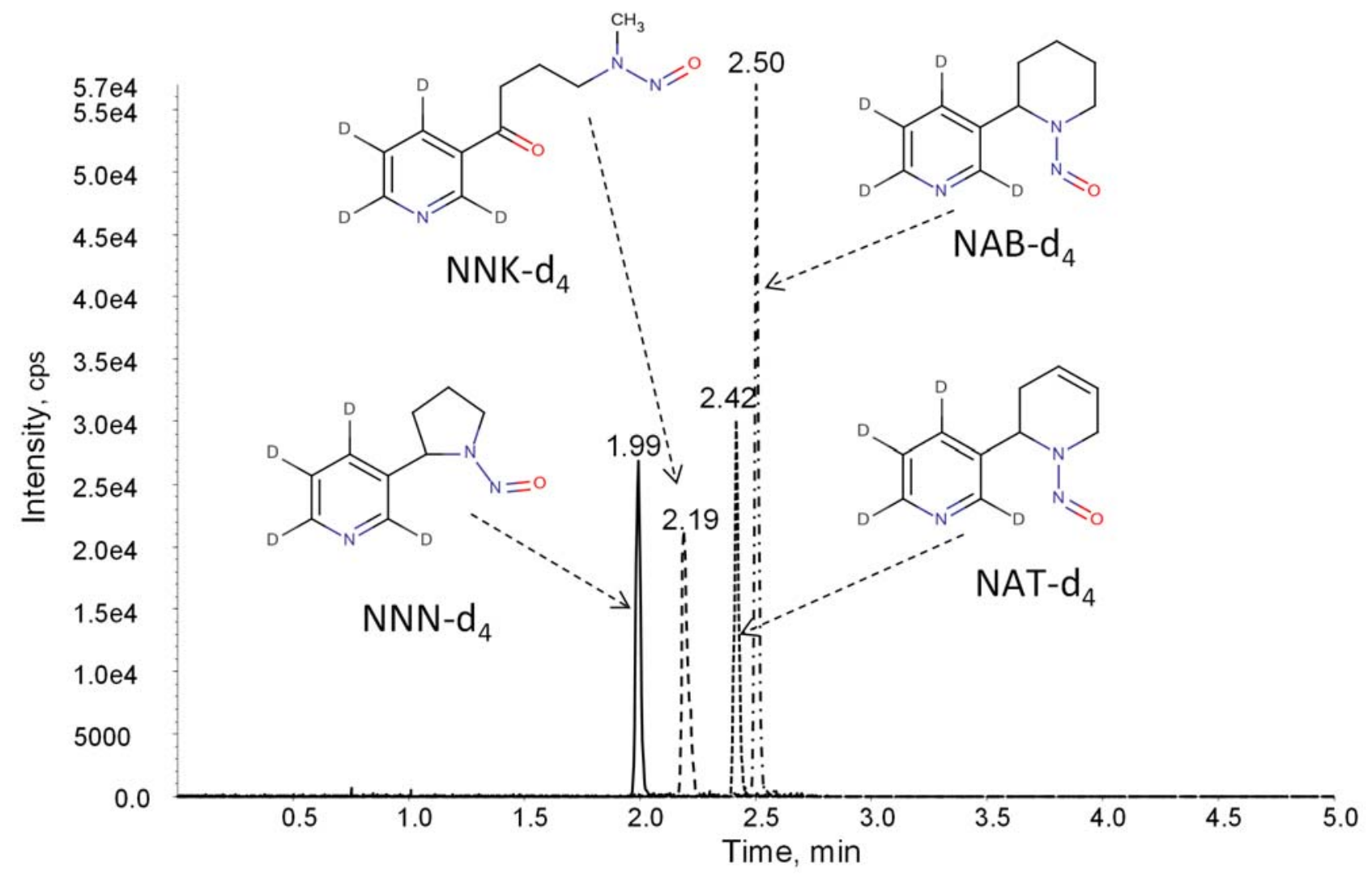

Figure 3. Chromatogram of four internal standards, NAB-d4 at $0.835 \mathrm{ng} / \mathrm{mL}, \mathrm{NAT}-\mathrm{d} 4$ at $1.00 \mathrm{ng} / \mathrm{mL}, \mathrm{NNK}-\mathrm{d} 4 \mathrm{at} 1.00 \mathrm{ng} / \mathrm{mL}$ and NNN-d4 at $1.00 \mathrm{ng} / \mathrm{mL}$ obtained by a literature recommended method (12). 


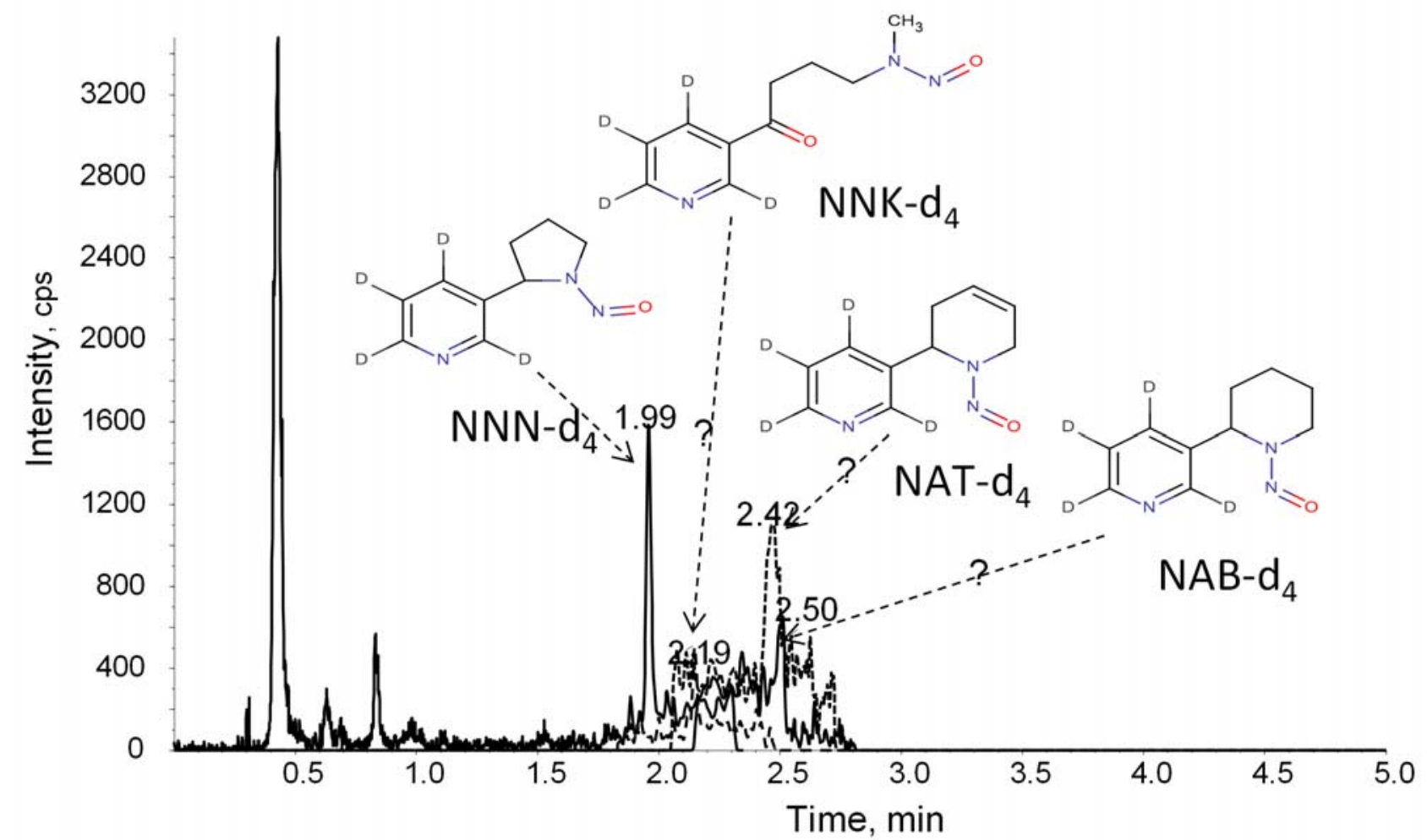

Figure 4. Chromatogram of four internal standards, NAB-d4 at $0.835 \mathrm{ng} / \mathrm{mL}, \mathrm{NAT}-\mathrm{d} 4$ at $1.00 \mathrm{ng} / \mathrm{mL}, \mathrm{NNK}-\mathrm{d} 4$ at $1.00 \mathrm{ng} / \mathrm{mL}$ and NNN-d4 at $1.00 \mathrm{ng} / \mathrm{mL}$ in the presence of $3 \%$ nicotine obtained by a literature recommended method (12).

dissolved in $10 \mathrm{~mL}$ extracting solution. Each sample was analyzed in three replicates, with each replicate injected three times in the LC-MS/MS instrument. The levels of TSNAs detected in each sample are indicated in Table 10. The results are expressed in TSNA in ng/g of nicotine. The RSD\% represents the relative standard deviation between the true replicates, and not between the results of different injections. The RSD\% between different injections of each sample were all below 5\%.

The results from Table 10 indicated that TSNAs are present at trace level in all USP grade nicotine samples. The NNN was found only at very low traces with one level below quantitation limit. All samples contained about 3-7 ng/g of NAB. The levels of NAT varied significantly between samples. The TSNA found at higher level was NNK present between 30 and $50 \mathrm{ng} / \mathrm{g}$ in all nicotine samples.

\section{Results for the analysis of TSNAs in e-liquids}

Two groups of e-liquid samples were evaluated in this study: 1) e-liquids from three e-cigarettes and 2) e-liquids from twelve e-tanks. Most samples were analyzed in triplicate. However in a few instances, only one analysis was performed due to the limited quantity of sample. A note will indicate such samples. Also, some results were generated for samples that had in the analyzed solution a level below the lowest standard. The results for TSNAs (in $\mathrm{ng} / \mathrm{g}$ ) for the e-liquids are given in Table 11.

The results for TSNAs (in $\mathrm{ng} / \mathrm{g}$ ) for the e-liquids from e-tanks are given in Table 12.

The results from Table 12 indicate e-liquid from several Blu e-liquids were relatively high in TSNAs, while Vuse both Original and Menthol, and Njoy were very low in TSNAs. A

Table 10. Results of TSNAs in nicotine expressed as $\mathrm{ng} / \mathrm{g}$.

\begin{tabular}{|c|c|c|c|c|c|c|c|c|}
\hline Sample & NAB & RSD\% & NAT & RSD\% & NNK & RSD\% & NNN & RSD\% \\
\hline TRC nicotine & $0.015^{a}$ & - & $0.018^{a}$ & - & N.D. ${ }^{b}$ & - & $0.002^{a}$ & - \\
\hline Spl. Nicotine 1 & 6.306 & 16.2 & 4.360 & 21.7 & 31.127 & 8.9 & $0.415^{a}$ & 22.7 \\
\hline Spl. Nicotine 2 & 7.247 & 4.1 & 19.047 & 6.2 & 50.757 & 1.0 & 2.084 & 17.8 \\
\hline Spl. Nicotine 3 & 5.821 & 19.9 & 21.852 & 9.6 & 34.678 & 2.9 & 1.710 & 17.1 \\
\hline Spl. Nicotine 4 & 3.340 & 2.5 & 3.927 & 8.2 & 31.292 & 7.4 & 1.067 & 18.1 \\
\hline
\end{tabular}

a The analyzed solution had a level below LOQ.

b Not detected. 
Table 11. Results of TSNAs in $\mathrm{ng} / \mathrm{g}$ for e-liquid separated from e-cigarettes (averages of three replicates).

\begin{tabular}{|c|c|c|c|c|c|c|c|c|}
\hline Sample & NNN & $\begin{array}{c}\text { RSD\% } \\
\text { NNN }\end{array}$ & NAT & $\begin{array}{c}\text { RSD } \% \\
\text { NAT }\end{array}$ & NAB & $\begin{array}{c}\text { RSD } \% \\
\text { NAB }\end{array}$ & NNK & $\begin{array}{c}\text { RSD\% } \\
\text { NNK }\end{array}$ \\
\hline $\mathrm{V} 2^{\mathrm{a}}$ & 7.886 & - & 47.609 & - & 3.980 & - & 3.858 & - \\
\hline Mark 10 & 0.887 & 17.7 & 0.535 & 6.0 & $0.024^{b}$ & 56.7 & 0.614 & 22.4 \\
\hline Vuse Original (1) & 1.555 & 17.8 & 0.525 & 6.9 & 0.167 & 52.6 & 2.739 & 18.3 \\
\hline Vuse Original (2) & 1.374 & 18.1 & 0.524 & 10.2 & 0.137 & 68.1 & 2.749 & 24.7 \\
\hline
\end{tabular}

a Only one replicate analyzed.

b The value is below the lowest standard in the calibration curve.

Table 12. Results of TSNAs in $\mathrm{ng} / \mathrm{g}$ for e-liquid from e-tanks (averages of three replicates).

\begin{tabular}{|c|c|c|c|c|c|c|c|c|}
\hline Sample & NNN & $\begin{array}{l}\text { RSD\% } \\
\text { NNN }\end{array}$ & NAT & $\begin{array}{c}\text { RSD\% } \\
\text { NAT }\end{array}$ & NAB & $\begin{array}{c}\text { RSD } \% \\
\text { NAB }\end{array}$ & NNK & $\begin{array}{l}\text { RSD\% } \\
\text { NNK }\end{array}$ \\
\hline Vuse Original & $0.189^{a}$ & 2.1 & 0.305 & 1.0 & 0.010 & 82.2 & 0.000 & - \\
\hline Vuse Menthol & 0.215 & 5.1 & 0.311 & 4.2 & 0.011 & 27.4 & 0.000 & - \\
\hline Njoy & 0.211 & 4.0 & 0.304 & 1.7 & 0.015 & 25.8 & 0.041 & 79.2 \\
\hline Blu NRG & 0.264 & 5.9 & 0.690 & 8.6 & 0.019 & 63.0 & 0.116 & 17.9 \\
\hline Blu Rich Tobacco & 1.621 & 4.8 & 9.845 & 2.9 & 0.225 & 3.3 & 1.100 & 13.0 \\
\hline Blu Classic & 0.823 & 2.7 & 2.704 & 5.5 & 0.233 & 3.8 & 1.159 & 9.0 \\
\hline Blu Menthol & 1.567 & 1.5 & 29.308 & 3.3 & 2.779 & 2.3 & 0.708 & 21.2 \\
\hline Blu Bluberry & 0.278 & 2.7 & 0.996 & 2.9 & 0.072 & 4.7 & 1.695 & 2.7 \\
\hline Blu Tobacco Gold & 4.083 & 2.5 & 13.023 & 1.4 & 1.165 & 3.9 & 1.380 & 6.8 \\
\hline Blu Strawb. Mint & 0.220 & 8.8 & 1.371 & 1.6 & 0.097 & 45.3 & 2.075 & 3.1 \\
\hline Blu Vanilla & 3.129 & 3.1 & 6.601 & 2.8 & 0.562 & 5.2 & 0.091 & 43.3 \\
\hline Blu Cherry & 0.238 & 16.7 & 0.648 & 7.5 & 0.044 & 38.0 & 0.002 & 86.6 \\
\hline
\end{tabular}

a The values in italics are below the lowest standard in the calibration curve.

Table 13. Results of TSNAs in the particulate phase from e-cigarettes expressed in $\mathrm{ng} / 20$ puffs (averages of three replicates).

\begin{tabular}{|c|c|c|c|c|c|c|c|c|}
\hline Sample & NNN & $\begin{array}{l}\text { RSD } \% \\
\text { NNN }\end{array}$ & NAT & $\begin{array}{c}\text { RSD } \% \\
\text { NAT }\end{array}$ & NAB & $\begin{array}{c}\text { RSD } \% \\
\text { NAB }\end{array}$ & NNK & $\begin{array}{c}\text { RSD\% } \\
\text { NNK }\end{array}$ \\
\hline Mark 10 & $0.170^{a}$ & 6.5 & 0.102 & 6.0 & 0.003 & 24.4 & 0.056 & 16.6 \\
\hline Vuse Original (1) & 0.225 & 36.0 & 0.113 & 11.0 & 0.039 & 25.7 & 0.043 & 5.1 \\
\hline Vuse Original (2) & 0.143 & 22.3 & 0.101 & 7.7 & 0.013 & 41.5 & 0.022 & 32.4 \\
\hline Blu Classic & 2.499 & 14.7 & 0.977 & 33.3 & 0.356 & 3.1 & 0.423 & 25.8 \\
\hline V2 & 0.933 & 14.8 & 3.422 & 24.0 & 0.311 & 24.7 & 0.403 & 19.2 \\
\hline
\end{tabular}

a The values in italics are below the lowest standard in the calibration curve.

relatively high level of NAT was detected in Blu Menthol and Blu Tobacco Gold. The e-liquid from Blu tobacco Gold was also relatively high in NNN. Some RSD\% values for the samples were high, not uncommon for such low level of analyte.

Results for the analysis of TSNAs in particulate phase of electronic smoking devices

The results for TSNAs in the particulate phase from e-cigarettes expressed in $\mathrm{ng} / 20$ puffs are given in Table 13 (average of three replicates). The values for TSNAs per $g$ of collected aerosols are given in Table 14. The total number of puffs collected was 100. For Vuse Original, two sets of e-cigarettes were analyzed. Each set consisted of three replicates.
Table 14. Results of TSNAs in the particulate phase from e-cigarettes expressed in $\mathrm{ng} / \mathrm{g}$ collected aerosols (averages of three replicates).

\begin{tabular}{l|r|r|r|r|r}
\hline Sample & $\begin{array}{r}\text { Weight } \\
\text { (g/100 } \\
\text { puffs })\end{array}$ & NNN & NAT & NAB & NNK \\
\hline Mark 10 & 0.282 & 3.019 & 1.811 & 0.053 & 0.994 \\
Vuse Original (1) & 0.243 & 4.622 & 2.321 & 0.801 & 0.883 \\
Vuse Original (2) & 0.241 & 2.967 & 2.095 & 0.270 & 0.456 \\
Blu Classic & 0.199 & 62.905 & 24.593 & 8.961 & 10.648 \\
V2 & 0.328 & 14.243 & 52.239 & 4.748 & 6.152 \\
\hline
\end{tabular}


Table 15. Results of TSNAs in the particulate phase from e-tanks expressed in $\mathbf{n g} / 20$ puffs (averages of three replicates).

\begin{tabular}{l|c|c|c|c|c|c|c|c}
\hline Sample & NNN & $\begin{array}{c}\text { RSD\% } \\
\text { NNN }\end{array}$ & NAT & $\begin{array}{c}\text { RSD\% } \\
\text { NAT }\end{array}$ & NAB & $\begin{array}{c}\text { RSD\% } \\
\text { NAB }\end{array}$ & $\begin{array}{c}\text { NNK } \\
\text { RSD\% } \\
\text { NNK }\end{array}$ \\
\hline Vuse Original & 0.140 & 29.0 & $0.048^{a}$ & 5.5 & 0.002 & 65.6 & 0.010 & 83.2 \\
Vuse Menthol & 0.113 & 18.2 & 0.047 & 3.2 & 0.003 & 65.1 & 0.001 & 44.9 \\
Smok & 0.108 & 24.9 & 0.055 & 12.1 & 0.002 & 39.1 & 0.057 & 14.8 \\
Blu Classic $^{\text {b }}$ & 0.142 & - & 0.078 & - & 0.003 & - & 0.035 & - \\
Njoy $^{\text {b }}$ & 0.107 & - & 0.047 & - & 0.002 & - & 0.015 & - \\
\hline
\end{tabular}

a The values in italics are below the lowest standard in the calibration curve.

b Only one replicate analyzed.

Table 16. Results of TSNAs in the particulate phase from e-tanks expressed in $\mathrm{ng} / \mathrm{g}$ collected aerosols (averages of three replicates).

\begin{tabular}{l|c|c|c|c|c}
\hline Sample & $\begin{array}{c}\text { Weight } \\
\text { (g/200 } \\
\text { puffs) }\end{array}$ & NNN & NAT & NAB & NNK \\
\hline Vuse Original & 0.791 & 1.770 & $0.607^{a}$ & 0.025 & 0.126 \\
Vuse Menthol & 0.561 & 2.013 & 0.837 & 0.053 & 0.018 \\
Smok & 0.227 & 4.749 & 2.419 & 0.088 & 2.507 \\
Blu Classic & 0.757 & 1.876 & 1.030 & 0.040 & 0.462 \\
Njoy & 0.634 & 1.688 & 0.742 & 0.032 & 0.237 \\
\hline
\end{tabular}

a The values in italics are below the lowest standard in the calibration curve.

The results from Table 13 indicate that the particulate phase from Blu Classic and V2 e-cigarettes were significantly higher than the levels from particulate phase from Mark 10 and Vuse Original e-cigarettes.

The results for TSNAs in the particulate phase from e-tanks expressed in ng/20 puffs are given in Table 15 (average of three replicates). The values for TSNAs per $\mathrm{g}$ of collected aerosols are given in Table 16. The total number of puffs collected was 200 .

The results from Table 15 indicate that the particulate phase from all the analyzed samples was very low in TSNAs.

\section{CONCLUSIONS}

A new method for TSNA analysis has been developed and validated, and the TSNAs were successfully analyzed in several USP grade nicotine samples. The method uses a LC-MS/MS technique with scheduled MRM. The novel procedure allows a good separation of TSNAs from the much larger nicotine peak, such that nicotine has no significant influence on TSNAs quantitation. The levels of TSNAs in the USP grade nicotine samples were very low, except for NNK that although low was found in the range of $30-50 \mathrm{ng} / \mathrm{g}$. The method was also successfully applied for the analysis of TSNAs in several e-liquids and particulate phase condensate from commercially available e-cigarettes and e-tanks. With few exceptions, the levels of TSNAs in all the analyzed samples were also very low.

\section{REFERENCES}

1. Stepanov, I., S.G. Carmella, S.S. Hecht, and G. Duca: Analysis of Tobacco-Specific Nitrosamines in Moldovan Cigarette Tobacco; J. Agric. Food Chem. 50 (2002) 2793-2797. DOI: 10.1021/jf011552j

2. Wu, W., D.L. Ashley, and C.H. Watson: Simultaneous Determination of Five Tobacco-Specific Nitrosamines in Mainstream Cigarette Smoke by Isotope Dilution Liquid Chromatography/Electrospray Ionization Tandem Mass Spectrometry; Anal. Chem. 75 (2003) 4827-4832. DOI: 10.1021/ac030135y

3. Jansson, C., A. Paccou, and B.G. Oesterdahl: Analysis of Tobacco-Specific $N$-Nitrosamines in Snuff by Ethyl Acetate Extraction and Liquid Chromatography-Tandem Mass Spectrometry; J. Chromatogr. A 1008 (2003) 135-143. DOI: 10.1016/S0021-9673(03)00981-6

4. Österdahl, B.-G., C. Jansson, and A. Paccou: Decreased Levels of Tobacco-Specific $N$-Nitrosamines in Moist Snuff on the Swedish Market; J. Agric. Food Chem. 52 (2004) 5085-5088. DOI: 10.1021/jf049931a

5. Wagner, K.A., N.H. Finkel, J.E. Fossett, and I.G. Gillman: Development of a Quantitative Method for the Analysis of Tobacco-Specific Nitrosamines in Mainstream Cigarette Smoke Using Isotope Dilution Liquid Chromatography/Electrospray Ionization Tandem Mass Spectrometry; Anal. Chem. 77 (2005) 1001-1006. DOI: $10.1021 / \mathrm{ac} 048887 \mathrm{v}$

6. Stepanov, I., J. Jensen, D. Hatsukami, and S.S. Hecht: Tobacco-Specific Nitrosamines in New Tobacco Products; Nicotine Tob. Res. 8 (2006) 309-313. DOI: $10.1080 / 14622200500490151$

7. Wu, J., P. Joza, M. Sharifi, W.S. Rickert, and J.H. Lauterbach: Quantitative Method for the Analysis of Tobacco-Specific Nitrosamines in Cigarette Tobacco and Mainstream Cigarette Smoke by Use of Isotope Dilution Liquid Chromatography Tandem Mass Spectrometry; Anal. Chem. 80 (2008) 1341-1345. DOI: $10.1021 / \mathrm{ac} 702100 \mathrm{c}$

8. Moldoveanu, S.C. and M. Borgerding: Formation of Tobacco Specific Nitrosamines in Mainstream Cigarette Smoke; Part 1, FTC Smoking; Beitr. Tabakforsch. Int. 23 (2008) 19-31. DOI: 10.2478/cttr-2013-0845

9. Sleiman, M., R.L. Maddalena, L.A. Gundel, and H. Destaillats: Rapid and Sensitive Gas ChromatographyIon-Trap Tandem Mass Spectrometry Method for the Determination of Tobacco-Specific $N$-Nitrosamines in 
Secondhand Smoke; J. Chromatogr. A 1216 (2009) 7899-7905. DOI: 10.1016/j.chroma.2009.09.020

10. Xiong, W., H. Hou, X. Jiang, G. Tang, and Q. Hu: Simultaneous Determination of Four Tobacco-Specific $\mathrm{N}$-Nitrosamines in Mainstream Smoke for Chinese Virginia Cigarettes by Liquid Chromatography-Tandem Mass Spectrometry and Validation Under ISO and "Canadian Intense" Machine Smoking Regimes; Anal. Chim. Acta 674 (2010) 71-78.

DOI: $10.1016 /$ j.aca.2010.06.011

11. Kim, H.-J. and H.-S. Shin: Determination of TobaccoSpecific Nitrosamines in Replacement Liquids of Electronic Cigarettes by Liquid ChromatographyTandem Mass Spectrometry; J. Chromatogr. A 1291 (2013) 48-55. DOI: 10.1016/j.chroma.2013.03.035

12. Zhu, J., N. Qian, S. Jones, and S. Moldoveanu: A Versatile Method for the Analysis of TSNAs in Tobacco Products and Cigarette Smoke by LC-MS-MS; $69^{\text {th }}$ Tobacco Science Research Conference, Poster 73, Naples, Florida, USA, Sept 20-23, 2015.

13. Zhang, J., R. Bai, X. Yi, Z. Yang, X. Liu, J. Zhou, and W. Liang: Fully Automated Analysis of Four TobaccoSpecific $N$-Nitrosamines in Mainstream Cigarette Smoke Using Two-Dimensional Online Solid Phase Extraction Combined with Liquid ChromatographyTandem Mass Spectrometry; Talanta 146 (2016) 216-224. DOI: 10.1016/j.talanta.2015.08.057
14. Farsalinos, K.E., G. Gillman, K. Poulas, and V. Voudris: Tobacco-Specific Nitrosamines in Electronic Cigarettes: Comparison Between Liquid and Aerosol Levels; Int. J. Environ. Res. Public Health 12 (2015) 9046-9053. DOI: 10.3390/ijerph120809046

15. Moldoveanu, S., J. Zhu, and N. Qian: Analysis of TSNAs in Nicotine Used as a Component in E-Liquids; $70^{\text {th }}$ Tobacco Science Research Conference, Paper 38, Palm Beach Gardens, Florida, USA, Sept 18-21, 2016.

16. Jin, X., J.W. Flora, and K.A. Wagner: Determination of Tobacco-Specific Nitrosamines in Electronic Cigarette Liquids and Aerosols by UPLC/MS/MS; $70^{\text {th }}$ Tobacco Science Research Conference, Poster 12, Palm Beach Gardens, Florida, USA, Sept 18-21, 2016.

17. Moldoveanu, S.C. and V. David: Modern Sample Preparation for Chromatography, Elsevier, Amsterdam, The Netherlands, 2015.

Corresponding author:

Serban C. Moldoveanu

R.J. Reynolds Tobacco Co.

Winston-Salem, NC

USA

E-mail:moldovs@rjrt.com 
